\title{
Moving the pulsed heating technique beyond monolithic specimens: Experiments with coated wires
}

\author{
D. Josell, D. Basak, J.L. McClure, U.R. Kattner, M.E. Williams, and W.J. Boettinger \\ Metallury Division, National Institute of Standards and Technology, Gaithersburg, Maryland \\ M. Rappaz \\ Department of Materials, Ecole Polytechnique Federal Lausanne, Lausanne, Switzerland
}

(Received 29 January 2001; accepted 5 June 2001)

\begin{abstract}
Pulsed heating experiments that measure high-temperature thermophysical properties using pyrometric measurement of the temperature-time history of metal specimens rapidly heated by passage of electric current have a 30-year history at the National Institute of Standards and Technology. In recent years, efforts have been made to move beyond the limitations of the standard technique of using costly, black-body geometry specimens. Specifically, simultaneous polarimetry measurement of the spectral emissivity has permitted study of sheet and wire specimens. This paper presents the results of two efforts to expand beyond the macroscopically monolithic, single-phase materials of all previous studies. In the first study the melting temperatures of coatings, including $\mathrm{Ti}$ and $\mathrm{Ti}(\mathrm{Al})$ alloys, deposited on higher melting Mo substrates are measured. In the second study the melting temperatures of substrates, $\mathrm{Ti}$ and $\mathrm{Cr}$, covered by higher melting $\mathrm{W}$ and Mo coatings are measured.
\end{abstract}

\section{INTRODUCTION}

Pulsed heating experiments based on pyrometric and electrical measurement of the temperature-time history of metal specimens rapidly heated by passage of electric current have been used to obtain melting temperatures, specific heats, and latent heats at the National Institute of Standards and Technology (NIST) for the past 30 years. ${ }^{1,2}$ Electrical and magnetic issues related to the pulsed current in these experiments are detailed in Ref. 2 in particular; for the currents and pulse times in these experiments, spatial variation of current density due to such effects is negligible. Early experiments utilized tubular specimens with small sighting holes to approximate black-body conditions. The pyrometer is focused on the hole, and the experimentally measured pyrometer voltages can be directly converted to true temperatures without knowledge of the spectral emissivity of the specimen at the pyrometer wavelength. Such experiments provide thermodynamic data for elemental materials at elevated temperatures, with uncertainties in determination of, e.g., melting temperature as small as those associated with the pyrometric determination of temperature, typically approximately $8 \mathrm{~K}(2 \sigma)$ at temperatures near $2000 \mathrm{~K}$. A significant drawback of such specially prepared specimens is their cost.

Some recent efforts attempt to move beyond the limitations of this standard technique. Specifically, polarimetric measurement of the spectral emissivity of the specimen surface, concurrent with pyrometric measurement of the radiance temperature on the same surface, has permitted study of sheet and wire specimens ${ }^{3}$ rather than costly black-body geometry specimens. Such a technique permitted a study of the impact of heating rate and grain size on the melting behavior exhibited by a $\mathrm{Nb}-47$ mass\% Ti alloy. ${ }^{4}$ The savings do come with other "costs", specifically loss of accuracy in temperature determination caused by inclusion of an additional real-time measurement (spectral emissivity). However, the accuracy is still significantly higher than that of other experimental techniques, e.g., visual observation of melting. For refractory metals and alloys, where many melting temperatures have uncertainties approaching or exceeding $100 \mathrm{~K}$ (see below), the enhanced versatility of such a technique far outweighs the increased uncertainty of the measurements. It is in the spirit of further increasing the versatility of the technique that this paper moves beyond the macroscopically monolithic, singlephase materials of previous studies. All temperatures given in this paper are true temperatures computed using Planck's law and the measured emissivities and radiance temperatures.

Two separate types of experiments are detailed. The first study is of the melting behavior of lower melting coatings, particularly $\mathrm{Ti}$ and $\mathrm{Ti}(\mathrm{Al})$ alloys, deposited on higher melting Mo substrates. The second study is of the melting behavior of lower melting substrates, particularly $\mathrm{Ti}$ and $\mathrm{Cr}$, covered by higher melting Mo or W/Mo 
coatings. In both cases a current of 500-1500 A resistively heats the specimen through the duration of the experiment, typically 50 to $100 \mathrm{~ms}$ from the initial application of the current until the inception of melting and subsequent failure. The experiments with the pure Ti as coating or substrate are meant to assess the accuracy of such experiments through comparison of the measured melting temperatures to the known melting temperature of $\mathrm{Ti}\left(T_{\mathrm{m}}=1943 \pm 2 \mathrm{~K}\right)$. The experiments with the $\mathrm{Ti}(\mathrm{Al})$ coatings subsequently apply the technique to measure melting temperatures of alloy compositions in an industrially relevant binary phase diagram. The experiments with the $\mathrm{Cr}$ coated with Mo or W/Mo measure the poorly known melting point of elemental $\mathrm{Cr}$; the high vapor pressure of $\mathrm{Cr}$ at temperatures approaching its melting point prevents accurate determination of this temperature by most techniques. Use of both low-oxygen content and high-oxygen content "99.99\% (metals basis)" $\mathrm{Cr}$ permit evaluation of features on the $\mathrm{Cr}-\mathrm{O}$ binary phase diagram as well.

\section{SPECIMEN PREPARATION}

All coatings were deposited by electron beam evaporation. The deposition system has three separate sources and a base pressure of approximately $10^{-6} \mathrm{~Pa}\left(10^{-8}\right.$ torr). Titanium approximately $0.5-\mu \mathrm{m}$ thick was preevaporated on the walls of the deposition chamber at the start of deposition to eliminate contamination caused by outgassing from the chamber walls. Substrate surfaces were sputter-cleaned using ionized Ar from an in situ ion source prior to deposition of the coatings. For deposition of alloys, two sources were run simultaneously. Composition control was based on the individual deposition rates of the two sources as recorded by two quartz crystal monitors. Compositions quoted in this paper are measured compositions, obtained directly from cross sections of the coated specimens using energy dispersive $\mathrm{x}$-ray spectroscopy (EDS) with elemental standards in a scanning electron microscope.

For the $\mathrm{Ti}(\mathrm{Al})$ alloy depositions, a flat surface was polished on the side of the Mo rod with length equal to the length of the rod and width approaching the diameter of the rod. Deposits on this flat surface were smoother than those on the curved surface, exhibiting higher reflectivities, which improved the signal to noise of the measurements. The starting Al was $99.99 \%$ pure as specified by the manufacturer. The Ti source used for deposition of the coatings was prepared by the iodide process, having a $99.9 \%$ stated purity and measured oxygen and nitrogen contents of $10^{-4}$ at. $\%(100 \mathrm{ppm})$ and $10^{-5}$ at.\% (10 ppm), respectively. ${ }^{5}$ Additional nitrogen or oxygen pickup during deposition of the coatings cannot be ruled out. Titanium and $\mathrm{Ti}(\mathrm{Al})$ coatings were deposited on Mo (99.99\%) rods of 1.6-mm diameter (substrates) to study the melting behavior of the coatings. Interdiffusion of Mo into $\mathrm{Ti}$ and $\mathrm{Ti}(\mathrm{Al})$ only raises the solidus and liquidus temperatures. This ensures that the inception of melting corresponds to that of the pure material rather than that of any interdiffused region.

Microscopy (both optical and scanning electron) of 99.99\% (metals basis) $\mathrm{Cr}$ used as a substrate material indicated the presence of a second phase located at the grain boundaries. Composition analysis demonstrated that these 1 to $10 \mu \mathrm{m}$ diameter regions were oxygen rich, with atomic fractions between 46 and $58 \% \mathrm{Cr}$, with the remainder oxygen by difference. Such oxides are typical of "high-purity (metals basis)" Cr grown by electrodeposition. With oxide particles approximately $6 \mu \mathrm{m}$ in diameter spaced approximately $50 \mu \mathrm{m}$ apart (optical microscopy), this material had an oxide volume fraction of approximately $1 \%$ and, thus, an average of approximately 0.005 atomic fraction oxygen. This material is referred to as "high-oxygen" $\mathrm{Cr}$ in this paper. Also used as substrate material was $\mathrm{Cr}$ of purity $99.95 \%$ (metals basis) with $2.5 \times 10^{-4}$ atomic fraction oxygen (76 ppm by weight determined by the manufacturer); it is referred to as "low-oxygen" $\mathrm{Cr}$. The $\mathrm{Cr}$ was coated with $\mathrm{W}$ and $\mathrm{Mo}$ to study the melting behavior of the $\mathrm{Cr}$ substrates. The double W/Mo coating was used to prevent the formation of lower melting compositions by $\mathrm{Cr}-\mathrm{Mo}$ interdiffusion. No such regions exist in either the $\mathrm{Cr}-\mathrm{W}$ or $\mathrm{W}-\mathrm{Mo}$ phase diagrams. The Mo overlayer was used because deposition of a sufficiently thick layer of $\mathrm{W}$ alone was impractical. Nitrogen or oxygen pickup during deposition of the coatings is irrelevant since it does not affect the melting point of the $\mathrm{Cr}$ substrate material.

\section{RESULTS AND DISCUSSION: MELTING OF COATINGS}

\section{A. Pure titanium coatings}

Specimens were fabricated with $10 \mu \mathrm{m}$-thick Ti coatings on Mo rods. Experiments were conducted to determine the heating rates that sufficiently minimized interdiffusion between the coatings and substrate materials. The temperature at which the spectral emissivity exhibited a discontinuous decrease was taken as smoothing of the surface caused by melting. ${ }^{4}$ Data from 21 experiments are summarized in Fig. 1. The melting point is independent of heating rate above approximately $1 \times$ $10^{4} \mathrm{~K} \mathrm{~s}^{-1}$. The increase of melting temperature at slower heating rates is consistent with increased interdiffusion during the longer times associated with these experiments. Such interdiffusion was confirmed by EDS of cross-sectioned specimens obtained from experiments terminated prior to melting of the coating. The melting temperature measured at the highest heating rates (negligible interdiffusion) is approximately $10 \mathrm{~K}$ higher than the value of $1945 \mathrm{~K}$ obtained in this laboratory using pure 


\section{Melting of Titanium Coating on Molybdenum}

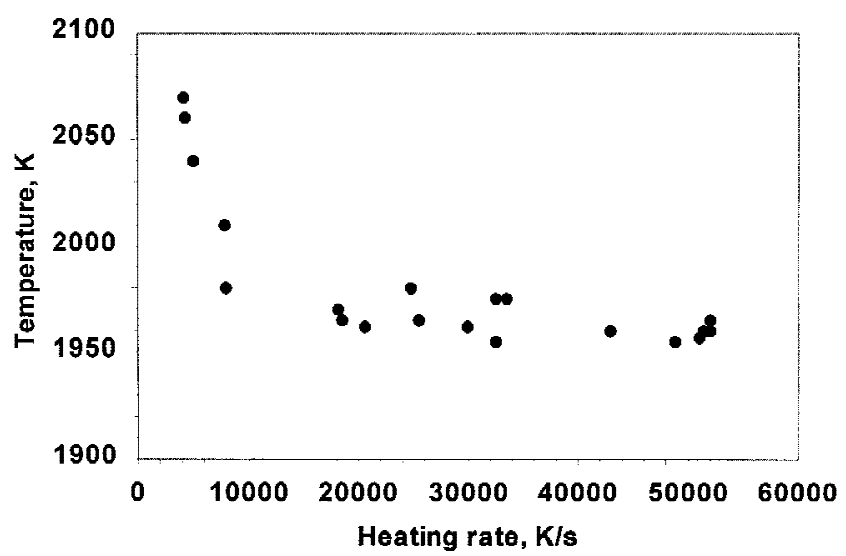

FIG. 1. Summary of the inception of melting for Ti coatings on Mo rod substrates plotted versus average heating rate. A clear trend is visible at heating rates less than approximately $10^{4} \mathrm{Ks}^{-1}$, with coatings melting at significantly higher temperatures due to interdiffusion of Mo from the substrate into the Ti coating.

Ti specimens. Note that, for monolithic materials of this type the steady-state difference in temperature between the center and surface of a $1.58 \mathrm{~mm}$ radius Mo rod due to radiative losses from the surface is only approximately $3 \mathrm{~K} .{ }^{4}$ Other values from the literature are between 1941 and $1943 \mathrm{~K}$. That the experimental value is higher than the accepted value might be indicative of oxygen or nitrogen in the films. For the materials of interest for study by this technique, an uncertainty of this size is acceptable.

The critical heating rate provides an experimental estimate of the effective diffusion rate for penetration of Mo into the Ti. The diffusion distance, $x$, for a constant heating rate, $\dot{T}$, is given by

$$
x^{2}=\frac{4 A}{\dot{T}}
$$

where

$$
A=\int_{T_{\mathrm{R}}}^{T_{\mathrm{M}}} D_{0} \exp [-Q / R T] \mathrm{d} T,
$$

for constant heating rate from room temperature to the melting temperature. For Mo penetration into Ti, $D_{0}=$ $0.24 \mathrm{~cm}^{2} \mathrm{~s}^{-1}$ and $Q=214.8 \mathrm{~kJ} \mathrm{~mol}^{-1}$, 6 giving a value for $A=5.2 \times 10^{-5} \mathrm{~cm}^{2} \mathrm{~K} \mathrm{~s}^{-1}$. For a heating rate of $1 \times 10^{4}$ $\mathrm{K} \mathrm{s}^{-1}, x=1.4 \mu \mathrm{m}$. However the experiments suggest that the penetration is about a factor of 10 greater than $1.4 \mu \mathrm{m}$, implying an experimental diffusion coefficient that is approximately 100 times larger than the published value. One possible explanation is a bulk diffusion coefficient in the evaporated thin films that is higher than the reported value due to a nonequilibrium (excess) concentration of point defects; highly defected crystalline structures are typical of thin films deposited on cooled substrates. The accelerated diffusion might also indicate the dominance of nonbulk diffusion paths, such as grain boundary diffusion.

\section{B. Titanium(aluminum) alloy coatings}

Specimens were fabricated with approximately $24 \mu \mathrm{m}$-thick $\mathrm{Ti}(\mathrm{Al})$ alloy coatings on Mo rods. These included six specimens with coatings of atomic fraction $0.19 \pm 0.01 \mathrm{Al}(2 \sigma$ for all stated uncertainties $)$ studied at heating rates between $7.0 \times 10^{4}$ and $9.5 \times 10^{4} \mathrm{~K} \mathrm{~s}^{-1}$ and four specimens with coatings of atomic fraction $0.31 \pm$ $0.01 \mathrm{Al}$ studied at heating rates between $2.2 \times 10^{4}$ and $6.2 \times 10^{4} \mathrm{~K} \mathrm{~s}^{-1}$. At these heating rates little penetration of Mo into the $\mathrm{Ti}(\mathrm{Al})$ coatings is expected. Figure 2 shows the radiance temperature and spectral emissivity recorded during a typical experiment along with the true temperature calculated from them. A short plateau of the true temperature, associated with the enthalpy of melting of the alloy coating, is observed. The flatness of the plateau is consistent with the small separation of the solidus and liquidus expected for this alloy (next section). For the Ti81 Al19 specimens, the plateau occurs at $1939 \pm 24 \mathrm{~K}$. For the Ti69Al31 alloy specimens, the plateau occurs at $1925 \pm 20 \mathrm{~K}$.

\section{Discussion of $\mathrm{Ti}$ and $\mathrm{Ti}(\mathrm{Al})$ alloy results}

The experimental data available in the literature for the Ti-Al liquidus and solidus ${ }^{7-9}$ are not considered reliable ${ }^{10}$ because the melting temperatures that were measured for pure $\mathrm{Ti}$ in those papers are 20 to $50 \mathrm{~K}$ higher than the currently accepted value. The lack of reliable data results in uncertainty in the phase diagram. Liquidus and solidus lines obtained in thermodynamic assessments

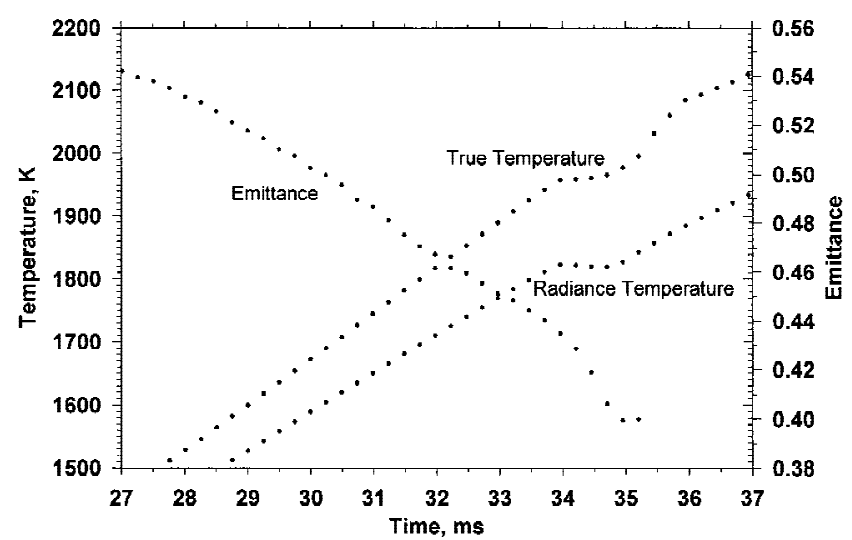

FIG. 2. Melting data for a $24 \mu$ m-thick, Ti81Al19 coating on a Mo substrate. The plot shows the radiance temperature recorded by the pyrometer (operating at $651 \mathrm{~nm}$ ), the spectral emissivity measured by the polarimeter (operating at $633 \mathrm{~nm}$ ), and the true temperature calculated from them using Planck's law. The difference in operating wavelengths for the two measurements leads to an error of less than 1 $\mathrm{K}$ for a Ti53Nb47 alloy. ${ }^{4}$ The plateau in the true temperature is associated with the enthalpy of melting for the alloy. 
predict behavior that ranges from a monotonic decrease with $\mathrm{Al}$ content ${ }^{10-12}$ to a congruent maximum. ${ }^{13,14}$ These features are shown in Fig. 3. The melting temperatures of the pure $\mathrm{Ti}$, Ti81Al19, and Ti69Al31 alloy coatings measured in this study, because they decrease monotonically with $\mathrm{Al}$ content, are inconsistent with the congruent maximum. They are consistent with the liquidus (rather than solidus) data reported for higher $\mathrm{Al}$ concentrations ${ }^{15}$ as seen in Fig. 3. Such is expected for rapid melting of an alloy. ${ }^{4}$

\section{RESULTS AND DISCUSSION: MELTING OF SUBSTRATES}

\section{A. Ti wires coated with Mo}

Two experiments were conducted on $\mathrm{Ti}$ wire with $10 \mu \mathrm{m}$-thick Mo coating at heating rates of $5.5 \times$ $10^{4} \mathrm{~K} \mathrm{~s}^{-1}$. Data from one experiment are shown in Fig. 4. The full melting plateau, associated with the latent heat of melting of the Ti wire, is obtained, which is not the case for uncoated specimens at these heating rates. The rapid decrease of the measured emissivity, indicating melting of the surface, and subsequent rapid failure ( $<2 \mathrm{~ms}$ later) of the specimen occur only after the end of the plateau. Thus, some thickness of the encapsulating solid Mo coating survives melting of the entire Ti wire. The relatively gradual change of slope toward the end of the plateau, as compared to the sharp corner at the start of the plateau, is likely a result of steadily increasing Mo concentration in the melt; this dissolution of the Mo coating ultimately leads to specimen failure. The plateau temperature of $1935 \mathrm{~K}(1933 \mathrm{~K}$ in the second

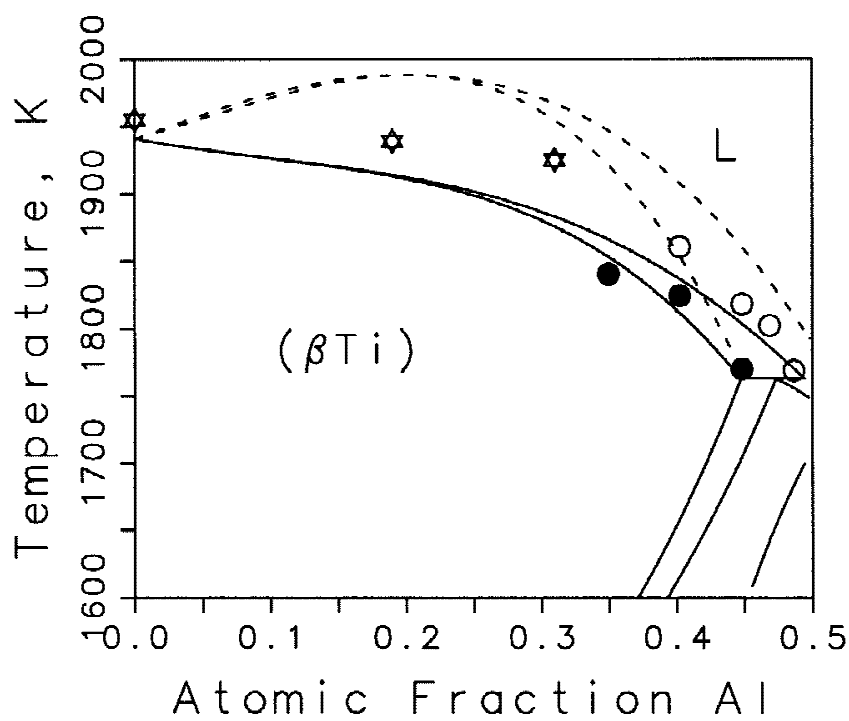

FIG. 3. Experimental data on the melting point for the $\mathrm{Ti}(\mathrm{Al})$ alloy coatings (stars) overlaid on the phase diagram calculated from thermodynamic assessments (solid, ${ }^{10}$ dashed $^{14}$ ) and DTA data ${ }^{15}$ (liquidus, empty circle; solidus, filled circle).

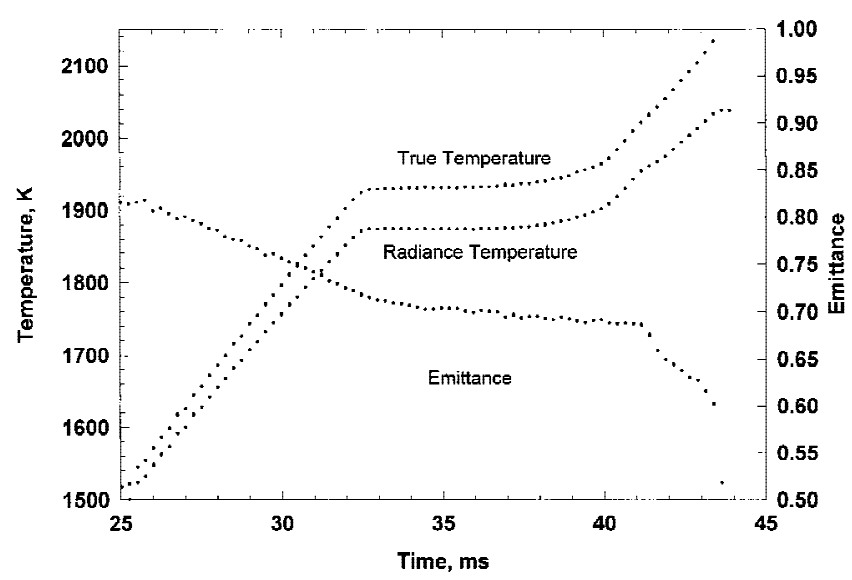

FIG. 4. Melting data for Ti rod coated with Mo. The plot shows the radiance temperature recorded by the pyrometer (operating at $651 \mathrm{~nm}$ ), the spectral emissivity measured by the polarimeter (operating at $633 \mathrm{~nm}$ ), and the true temperature calculated from them using Planck's law. The plateau in the true temperature is associated with the enthalpy of melting for the Ti. The rapid drop of the emissivity beyond $41 \mathrm{~ms}$ is associated with complete dissolution of the Mo coating that leads to failure of the now fully molten specimen.

experiment) is approximately $10 \mathrm{~K}$ below the melting temperature of $\mathrm{Ti}$, which will be addressed later. However, for the materials of interest for study by this technique, an uncertainty even of this size is acceptable.

\section{B. Cr wires (high-oxygen) coated with W/Mo}

The high-oxygen $\mathrm{Cr}$ was coated with approximately $1 \mu \mathrm{m} \mathrm{W}$ plus 15 to $20 \mu \mathrm{m}$ Mo. Temperatures obtained with uncoated strips were approximately $50 \mathrm{~K}$ lower than those obtained for coated specimens, probably because of the high $\mathrm{Cr}$ vapor pressure over the $\mathrm{Cr}$ surfaces, and are excluded from this work. Heating experiments were performed on (1) six coated $\mathrm{Cr}$ rods at heating rates of $1 \times$ $10^{4}$ to $3 \times 10^{4} \mathrm{~K} \mathrm{~s}^{-1}$, (2) four coated $\mathrm{Cr}$ strips at approximately $3 \times 10^{3} \mathrm{~K} \mathrm{~s}^{-1}$, and (3) five Cr black-body tubes (uncoated) at $3 \times 10^{3}$ to $4 \times 10^{3} \mathrm{~K} \mathrm{~s}^{-1}$, the tubes studied by pyrometry alone. A typical melting curve (Fig. 5) exhibits features not typical of a pure metal, viz., a discontinuous change in the slope of the temperature-time curves (approximately $1930 \mathrm{~K}$ ) and a sloping plateau (approximately $2040 \mathrm{~K}$ inception). Similar results were obtained for all three types of specimens, ruling out interdiffusion as the cause of either event. With the coated rods and strips the slope change was observed at $1910 \pm$ $15 \mathrm{~K}$; the blackbody tubes yielded $1925 \pm 10 \mathrm{~K}$. The plateau inception was observed with the coated rods and strips at $2050 \pm 20 \mathrm{~K}$; the blackbody tubes yielded $2060 \pm 10 \mathrm{~K}$. Note that both the slope change and plateau inception obtained with the W/Mo coated $\mathrm{Cr}$ are 10 to $15 \mathrm{~K}$ lower than those obtained using the blackbody geometry. The value obtained for the melting point of Mo coated Ti was also $10 \mathrm{~K}$ lower than the accepted value (Sec. IV. A). 


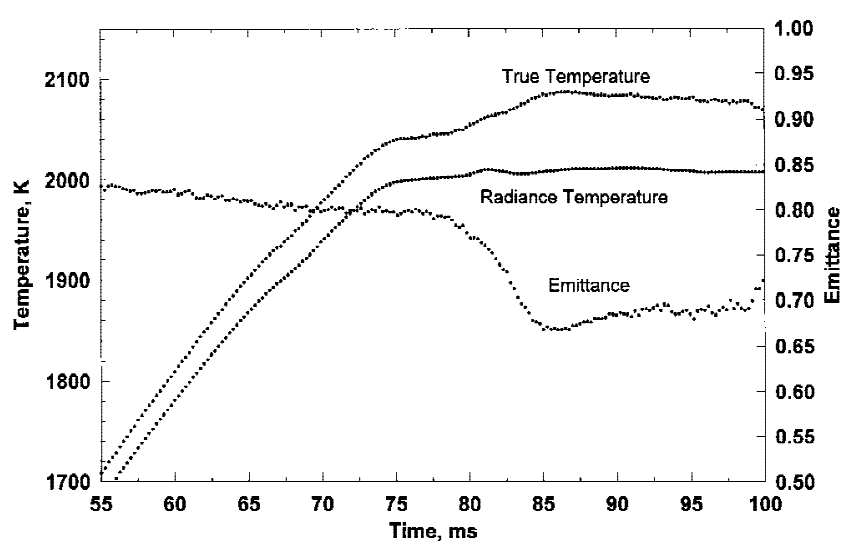

FIG. 5. Melting data for high-oxygen $\mathrm{Cr}$ rod coated with $\mathrm{W}$ and then Mo. The plot shows the radiance temperature recorded by the pyrometer (operating at $651 \mathrm{~nm}$ ), the spectral emissivity measured by the polarimeter (operating at $633 \mathrm{~nm}$ ), and the true temperature calculated from them using Planck's law. Note the deflection of the true temperature curve at $1930 \mathrm{~K}(67 \mathrm{~ms})$ and plateau inception at $2040 \mathrm{~K}$ (74 ms). The emissivity drop at $79 \mathrm{~ms}$ indicates $\mathrm{Cr}$ has broken through the Mo coating.

The probable source of this discrepancy is the roughness of the coated surfaces, which persists through melting of the underlying substrate material; the underlying theory for analyzing the polarimeter data assumes a smooth surface. The roughness manifests as values of emittance (Figs. 4 and 5) that are nearly twice the 0.3 to 0.4 value typical of the spectral emissivity of a smooth Mo surface in this range of temperature and wavelength. To correct for this systematic measurement error, $\mathrm{a}+10 \mathrm{~K}$ correction is made, where noted, to the temperatures computed from the measured emissivities and radiance temperatures using Planck's law. Thus the corrected experimental temperatures for the slope change and plateau inception are $1920 \pm 15$ and $2060 \pm 10 \mathrm{~K}$, respectively.

\section{Cr wires (low oxygen) coated with W/Mo}

The low-oxygen $\mathrm{Cr}$ was prepared with rectangular and square cross sections of $3.2 \mathrm{~mm} \times 1.6 \mathrm{~mm}$ and $1.6 \times$ $1.6 \mathrm{~mm}$, respectively. All were approximately $50 \mathrm{~mm}$ long. One side was polished on each specimen, and $1 \mu \mathrm{m}$ $\mathrm{W}$ followed by $11 \mu \mathrm{m}$ Mo was deposited on that side; the remaining three sides were coated with $0.3-\mu \mathrm{m} \mathrm{W}$ followed by $1 \mu \mathrm{m}$ Mo. The pyrometer and polarimeter observed the side with the thick coating in all experiments. Results of a typical experiment are shown in Fig. 6. On the basis of the emissivity and true temperature behaviors, the Mo coating survived through partial melting of the Cr. A short "preplateau" of at most $1.5 \mathrm{~ms}$ in duration is distinguishable at a corrected temperature of $2080 \pm$ $20 \mathrm{~K}$, in most experiments, prior to the main plateau (Fig. 6). For constant input power, a prediction of the time required to fully melt the specimen is obtained by

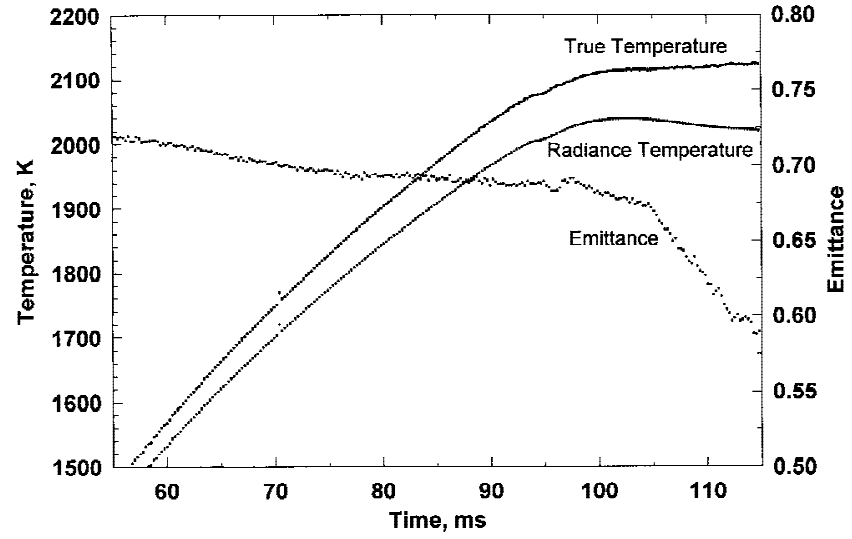

FIG. 6. Melting data for low-oxygen $\mathrm{Cr}$ rod coated with $\mathrm{W}$ and then Mo. The plot shows the radiance temperature recorded by the pyrometer (operating at $651 \mathrm{~nm}$ ), the spectral emissivity measured by the polarimeter (operating at $633 \mathrm{~nm}$ ), and the true temperature calculated from them using Planck's law. The main melting plateau $(2120 \mathrm{~K})$ is at the melting point of pure $\mathrm{Cr}$, with melting of approximately $3 \%$ of the specimen $(2070 \mathrm{~K})$ at the $\mathrm{Cr}-\mathrm{O}$ monotectic (discussed in Sec. IV. C).

dividing the latent heat by the specific heat and heating rate prior to the plateau. ${ }^{4}$ For $\mathrm{Cr}$ this is approximately $350 \mathrm{~K}$ divided by the heating rate which gives $35 \mathrm{~ms}$ at a heating rate of $1 \times 10^{4} \mathrm{~K} \mathrm{~s}^{-1}$. The preplateau thus corresponds to melting of at most $4 \%$ of the specimen; it is discussed in the next section. The corrected temperature of the main plateau, at which the bulk of melting occurs (see Fig. 6), is $2115 \pm 20 \mathrm{~K}$ from seven experiments. This temperature, $2115 \pm 20 \mathrm{~K}$, is the melting point of pure $\mathrm{Cr}$.

\section{Discussion of $\mathrm{Cr}$ results}

A version of the $\mathrm{Cr}-\mathrm{O}$ phase diagram from a selected source $^{17}$ is shown in Fig. 7. For the low-oxygen $\mathrm{Cr}$ $\left(2.5 \times 10^{-4}\right.$ atomic fraction oxygen $)$, the phase diagram predicts approximately $1 \%$ of the material should melt at the monotectic temperature $(2073 \mathrm{~K})$, with the rest melting, essentially, at the melting point of pure $\mathrm{Cr}(2133 \mathrm{~K})$. The corrected temperatures of the preplateau and main plateau observed during melting of the low-oxygen $\mathrm{Cr}$ are consistent with the monotectic and the Cr melting point on the phase diagram, respectively. The fraction melted during the preplateau is also consistent with the prediction of the phase diagram.

For the high-oxygen $\mathrm{Cr}(0.005$ atomic fraction oxygen), the phase diagram in Fig. 7 predicts approximately $1 \%$ of the material should melt at the eutectic temperature $(1933 \mathrm{~K})$ and approximately one-quarter of the material should melt at the monotectic temperature. Additional melting should occur as the temperature approaches the liquidus. Consistent with these predictions, the corrected slope-change and plateau-inception temperatures are quite close to the temperatures of the 


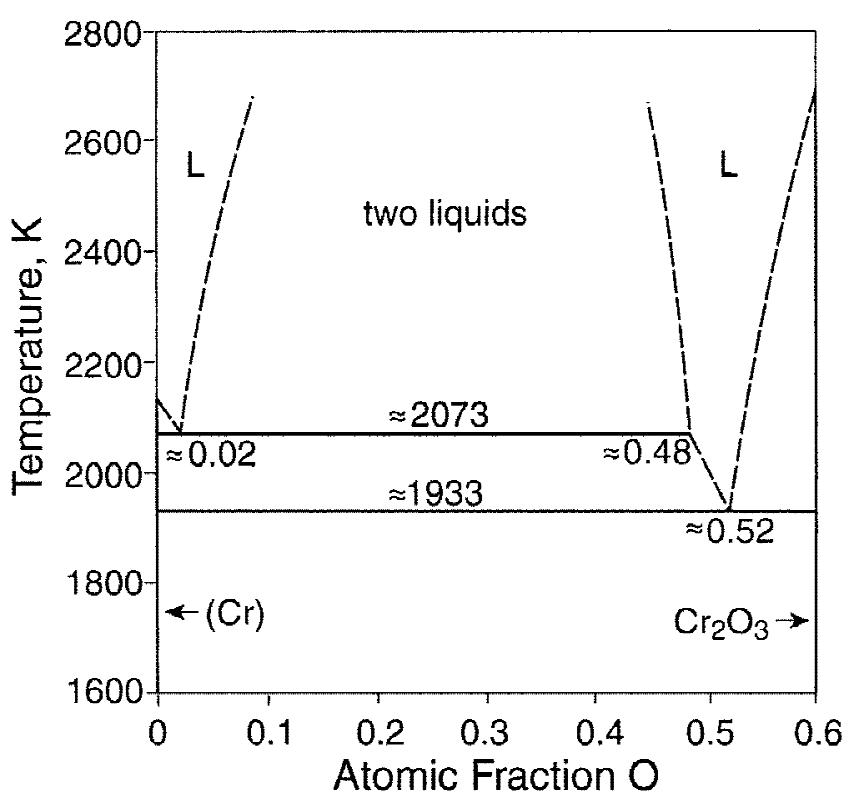

FIG. 7. Partial binary phase diagram for the $\mathrm{Cr}-\mathrm{O}$ system. ${ }^{17}$

eutectic and the monotectic on the phase diagram, respectively, with a weaker signal at the slope change (eutectic).

Values selected in compilations for the melting temperature of pure $\mathrm{Cr}$ vary by approximately $50 \mathrm{~K}$. Two graphical compilations of binary phase diagrams involving $\mathrm{Cr}$ with melting points for $\mathrm{Cr}$ of $2133 \mathrm{~K}^{17}$ and $2136 \mathrm{~K}^{16}$ are in reasonable agreement with the corrected value $2115 \pm 20 \mathrm{~K}$ obtained in this work. Analytical descriptions of the free energy of pure $\mathrm{Cr}$ in thermodynamic computations of binary phase diagrams use a higher melting point of $2180 \mathrm{~K},{ }^{18,19}$ inconsistent with the value obtained here. Phase diagrams for the $\mathrm{Cr}-\mathrm{O}$ system from various sources include an approximately $90 \mathrm{~K}$ range of values for the monotectic temperature: $2073 \mathrm{~K} ;{ }^{17}$ $2093 \mathrm{~K} ;{ }^{16} 2130 \mathrm{~K} ;{ }^{18} 2160 \mathrm{~K}{ }^{19}{ }^{1}$ [More recent thermodynamic based assessments, ${ }^{17,18}$ added the $\mathrm{Cr}_{3} \mathrm{O}_{4}$ phase into the phase diagram. For this case, the eutectic [ $\mathrm{L} \rightarrow$ $\left.(\mathrm{Cr})+\mathrm{Cr}_{3} \mathrm{O}_{4}\right]$ replaces $\left[\mathrm{L} \rightarrow(\mathrm{Cr})+\mathrm{Cr}_{2} \mathrm{O}_{3}\right]$ with only a small change in temperature.] The eutectic, monotectic, and pure Cr melting points of Ref. 17 (see Fig. 7) and Ref. 16 (for the eutectic) are consistent with the experimental data from both the high-oxygen and low-oxygen $\mathrm{Cr}$ specimens. Temperatures for the monotectic and pure $\mathrm{Cr}$ melting points obtained from the thermodynamic assessments ${ }^{18,19}$ are significantly higher than the corresponding experimental values.

\section{MODELING OF TEMPERATURE DISTRIBUTIONS IN COATED SPECIMENS}

The heating rates, $\dot{T}$, in these experiments are sufficiently fast $\left(1 \times 10^{4}\right.$ to $\left.5 \times 10^{4} \mathrm{~K} \mathrm{~s}^{-1}\right)$ that the specimens can be considered adiabatic; radiated power is only approximately $1 \%$ of the input power. ${ }^{20}$ Since continuous current is used, the density of current, $j$, and thus the heat source term, $\dot{H}=\rho j^{2}$, would be uniform if the electrical resistivity, $\rho$, were uniform. As can be seen in Table I, the room-temperature resistivity of $\mathrm{W}$ and $\mathrm{Mo}$ are nearly the same, but that of $\mathrm{Cr}$ is more than twice as large and that of $\mathrm{Ti}$ is nearly eight times larger. However, using the temperature-dependent properties shown for Mo and Ti in Table II, by $2000 \mathrm{~K}$ the resistivity of Ti is only twice as large. Considering the two materials of the substrate (s) and coating (c), for specimen length much greater than radius, one can write

$$
E=\rho_{\mathrm{s}} j_{\mathrm{s}}=\rho_{\mathrm{c}} j_{\mathrm{c}}
$$

where $E$ is the electrical field (i.e., the voltage/unit length) in the wire and currents are presumed uniform within both the coating and the substrate. The Joule source terms in the two media are therefore given by the following relationship:

$\dot{H}_{\mathrm{s}}=E j_{\mathrm{s}}=\frac{E^{2}}{\rho_{\mathrm{s}}}=\frac{\rho_{\mathrm{c}}}{\rho_{\mathrm{s}}} \dot{H}_{\mathrm{c}} \quad$ or $\quad \frac{\dot{H}_{\mathrm{s}}}{\dot{H}_{\mathrm{c}}}=\left[\frac{\rho_{\mathrm{s}}}{\rho_{\mathrm{c}}}\right]^{-1}$.

The ratio of the Joule source terms is therefore inverse the ratio of the electrical resistivities.

The heat balance to be solved in the wire can be written as

$$
\frac{\partial h_{v}}{\partial t}=\frac{1}{\mathrm{r}} \frac{\partial}{\partial \mathrm{r}}\left[\kappa_{v} r \frac{\partial T}{\partial r}\right]+\dot{H}_{v} \quad v=\mathrm{s} \text { or } \mathrm{c},
$$

where $\kappa$ is the thermal conductivity and $h_{\nu}$ the volumetric enthalpy of phase $v$. The time derivative of the enthalpy can also be written:

$$
\frac{\partial h_{v}}{\partial t}=\left(c_{\mathrm{p}}\right)_{v} \frac{\partial \mathrm{T}}{\partial \mathrm{t}}-L_{v} \frac{\partial g_{\mathrm{s}}}{\partial t} \quad v=\mathrm{s} \text { or c },
$$

where $c_{\mathrm{p}}$ is the volumetric specific heat, $L_{\mathrm{v}}$ the volumetric latent heat of fusion, $g_{\mathrm{s}}$ the volume fraction of solid, and $T$ the temperature field. Continuity of the temperature at the substrate/coating interface has been assumed, and the latent heat (if remelting occurs) is released at the melting point. Using temperaturedependent thermal and electrical properties (Table II), Eqs. (5) and (6) have been solved using a simple 1dimensional finite volume program based on an implicit

TABLE I. Room-temperature properties of bulk elements. ${ }^{21}$

\begin{tabular}{lccc}
\hline \hline & $\begin{array}{c}\text { Resistivity, } \rho \\
\left(10^{-8} \Omega \mathrm{m}\right)\end{array}$ & $\begin{array}{c}\text { Conductivity, } \\
\left(\mathrm{W} \mathrm{m}^{-1} \mathrm{~K}^{-1}\right)\end{array}$ & $\begin{array}{c}\text { Specific heat, } c_{\mathrm{p}} \\
\left(10^{6} \mathrm{~J} \mathrm{~m}^{-3} \mathrm{~K}^{-1}\right)\end{array}$ \\
\hline $\mathrm{Cr}$ & 12.9 & 93.9 & 3.22 \\
$\mathrm{~W}$ & 5.65 & 177 & 2.59 \\
$\mathrm{Ti}$ & 42 & 22.4 & 2.35 \\
$\mathrm{Mo}$ & 5.2 & 139 & 2.52 \\
\hline \hline
\end{tabular}


TABLE II. Temperature-dependent properties ${ }^{\mathrm{a}}$ of bulk elements. ${ }^{22}$

\begin{tabular}{llll}
\hline \hline & Resistivity, $\rho\left(10^{-8} \Omega \mathrm{m}\right)$ & Conductivity, $\kappa\left(\mathrm{W} \mathrm{m}^{-1} \mathrm{~K}^{-1}\right)$ & Specific heat, $c_{\mathrm{p}}\left(10^{6} \mathrm{~J} \mathrm{~m}^{-3} \mathrm{~K}^{-1}\right)$ \\
\hline $\operatorname{Ti}(300: 1150) \mathrm{K}$ & $0.16 \mathrm{~T}$ & $20.9-1.25 \times 10^{-3} \mathrm{~T}$ & $2.07+9.4 \times 10^{-4} \mathrm{~T}$ \\
$\operatorname{Ti}(1150: 2000) \mathrm{K}$ & $134+0.012 \mathrm{~T}$ & $20.9-1.25 \times 10^{-3} \mathrm{~T}^{\mathrm{b}}$ & $1.79+9.4 \times 10^{-4} \mathrm{~T}$ \\
$\operatorname{Mo}(300: 2000) \mathrm{K}$ & $0.0205 \mathrm{~T}$ & $146-3.48 \times 10^{-2} \mathrm{~T}$ & $2.38+6.6 \times 10^{-4} \mathrm{~T}$ \\
\hline \hline
\end{tabular}

${ }^{a}$ Room-temperature values obtained from the expressions are consistent with those given in Table $\mathrm{I}^{21}$ except for the electrical resistivities, ${ }^{22}$ which are both approximately $20 \%$ higher.

${ }^{\mathrm{b}}$ Extrapolated from lower temperature data.

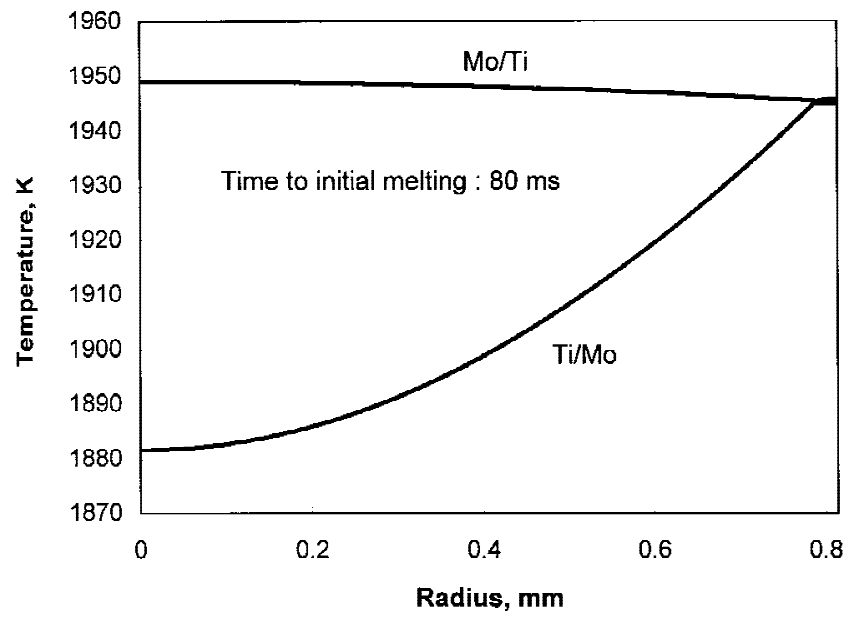

FIG. 8. Calculations of the temperature distributions in specimens composed of a coating of $\mathrm{Ti}$ on a Mo rod $(\mathrm{Mo} / \mathrm{Ti})$ and for a coating of Mo on a $\mathrm{Ti} \operatorname{rod}(\mathrm{Ti} / \mathrm{Mo})$. The temperature distributions are shown at approximately $80 \mathrm{~ms}$, with the coating $24-\mu \mathrm{m}$ thick and the rod $1.59 \mathrm{~mm}$ in diameter in both cases. Power inputs are such that the temperature at some location in the $\mathrm{Ti}$ has just reached the melting point of $\mathrm{Ti}(1945 \mathrm{~K})$.

scheme and a temperature recovery method (i.e., the temperature of a remelting volume element is held at the melting point until the corresponding value $g_{\mathrm{s}, \mathrm{v}}$ is equal to zero). As the process is nearly adiabatic during the very short heating times, the calculations were performed with a homogeneous Neumann condition at the surface of the coating.

The results of calculations of temperature distributions for a coating of $\mathrm{Ti}$ on a Mo rod and for a coating of Mo on a Ti rod are shown in Fig. 8. The input power is such that the inception of melting occurs at approximately $80 \mathrm{~ms}$, with the coating $24-\mu \mathrm{m}$ thick and the rod $1.59 \mathrm{~mm}$ in diameter in both cases. The calculations represent the temperature profile when the temperature at a location in the $\mathrm{Ti}$ first reaches the melting point (1945 K). The Mo heats more rapidly than the Ti because the ratio of the heat source term and the specific heat is larger for Mo than for Ti. For this reason, the Ti first melts at the $\mathrm{Ti} / \mathrm{Mo}$ interface. For the case of a Ti rod coated with Mo, most of the heating occurs in the Mo coating and thermal diffusion limitations result in a rather nonuniform temperature field. The temperature difference between the surface of the coating and the center of the wire is approximately $60 \mathrm{~K}$. In contrast, for a Mo rod is coated with $\mathrm{Ti}$, most of the heating occurs in the Mo wire and fast thermal diffusion through the thin coating results in a variation of only $3 \mathrm{~K}$ across the entire specimen (see Fig. 8).

On the basis of these calculations, experiments with the Ti coating on the Mo rod should be most accurate for measuring the melting point of Ti. Even though the Ti at the interface begins to melt prior to that on the surface viewed by the instruments, the temperature change across the thin coating is much less than $1 \mathrm{~K}$. There is no reason to expect a systematic error with specimens of this geometry.

For the Mo coating on the Ti rod specimens, the temperature rise across the Mo coating is also $\ll 1 \mathrm{~K}$ when the $\mathrm{Ti}$ at the interface begins to melt (Fig. 8). However, as further heating and melting occur, a temperature gradient will form in the liquid (absent convection). The Mo coating, and the molten Ti adjacent to it, will rise to temperatures above the melting point of $\mathrm{Ti}$, even while the inner region of the Ti rod is still in the process of melting. The increase in temperature evident in the latter part of the Ti melting plateau (Fig. 4) might be a manifestation of this, though Mo and Ti interdiffusion is also consistent with this increase. This effect is significantly smaller for the Mo-coated $\mathrm{Cr}$ specimens due to the similarity of the $\mathrm{Mo}$ and $\mathrm{Cr}$ resistivities (Table I) and the thinner coatings.

\section{UNCERTAINTIES}

The uncertainties associated with measurements obtained from the pyrometer and polarimeter in this approximate temperature range have been noted previously. ${ }^{4}$ In those results, uncertainty associated with the pyrometry was $7 \mathrm{~K}(2 \sigma)$; uncertainty associated with the polarimetry was $2 \%(5 \mathrm{~K})$. The resulting combined uncertainty was $10 \mathrm{~K}$. The scatter of the data for the Ti coatings on Mo as well as the Mo coatings on $\mathrm{Ti}$ are consistent with this $10 \mathrm{~K}$ uncertainty. The scatter in the data from the Ti81Al19- and Ti69Al31-coated specimens, noted to be 24 and $20 \mathrm{~K}$, respectively, are significantly larger (all uncertainties in this work are $2 \sigma$ ). The source of this additional scatter is believed to include 
some contribution from actual composition variation of the specimens. On the basis of these data, total measurement uncertainties of 25 and $22 \mathrm{~K}$ apply to these melting temperatures. The scatter in the results for the melting point of low-oxygen $\mathrm{Cr}, 20 \mathrm{~K}$, yields a total measurement uncertainty of $23 \mathrm{~K}$, including instrumental uncertainties, for the melting point of $\mathrm{Cr}$.

\section{CONCLUSIONS}

The results of two geometrically identical but fundamentally different types of pulsed heating experiments have been described for measuring melting temperatures. Both types of experiment use coated substrate specimens; the use of substrate materials with melting temperatures higher (lower) than that of the coating was shown to yield the melting temperature of the coating (substrate) material. Experiments with Ti coatings on Mo rods studied at different heating rates were used to quantify the experimental conditions required to overcome interdiffusion-induced artifacts. The results of studies with the Ti coatings on Mo substrates, as well as with $\mathrm{Ti}$ substrates coated with Mo, demonstrated the accuracy to be expected from such experiments. Results from $\mathrm{Ti}(\mathrm{Al})$ alloy coatings yielded melting temperature data helpful for understanding a portion of the Ti-Al phase diagram, demonstrating that a congruent maximum does not exist in the Ti-rich side. Measurement of the melting point of $\mathrm{Cr}$ through the use of coated $\mathrm{Cr}$ specimens yielded the melting point of $\mathrm{Cr}(2115 \pm 20 \mathrm{~K})$, demonstrating that the melting points used in thermodynamic assessments are at least $50 \mathrm{~K}$ too high. A monotectic and a eutectic temperature on the $\mathrm{Cr}-\mathrm{O}$ phase diagram were also obtained.

\section{REFERENCES}

1. A. Cezairliyan, M.S. Morse, H.A. Berman, and C.W. Beckett, J. Res. Natl. Bur. Stand. (U.S.) 74A, 65 (1970).
2. A. Cezairliyan, J. Res. Natl. Bur. Stand. (U.S.) 75C, 7 (1971).

3. A. Cezairliyan, S. Krishnan, and J.L. McClure, Int. J. Thermophys. 17, 1455 (1996).

4. D. Basak, W.J. Boettinger, D. Josell, S.R. Coriell, J.L. McClure, S. Krishnan, and A. Cezairliyan, Acta Mater. 47, 3147 (1999).

5. R.M. Waterstrat, Natl. Inst. Stand. Tech. Rep. NISTIR 88-3856, 1988.

6. Metals Reference Book, 5th ed., edited by C.J. Smithells (Butterworths, London, United Kingdom, 1976), p. 879, tracer diffusion coefficients for Mo in Ti.

7. H.R. Ogden, D.J. Maykuth, W.L. Finlay, and R.J. Jaffee, Trans. AIME 191, 1150 (1951).

8. E.S. Bumps, H.D. Kessler, and M. Hansen, Trans. AIME 194, 609 (1952).

9. I.I. Kornilov, E.N. Pylaeva, and M.A. Volkova, Izvest. Akad. Nauk SSSR, Otd. Khim. Nauk 7, 771 (1956).

10. U.R. Kattner, J-C. Lin, and Y.A. Chang, Metall. Trans. A 23A, 2081 (1992).

11. F. Zhang, S.L. Chen, Y.A. Chang, and U.R. Kattner, Intermetallics 5, 471 (1997).

12. I. Ohnuma, Y. Fujita, H. Mitsui, K. Ishikawa, R. Kainuma, and K. Ishida, Acta Mater. 48, 3133 (2000).

13. J.L. Murray, Metall. Trans. A 19A, 243 (1998)

14. N. Saunders, in COST 507, edited by I. Ansara, A.T. Dinsdale, and M.H. Rand (European Communities, Luxembourg, 1998), Vol. 2, pp. 89-95.

15. J.C. Mishurda and J.H. Perepezko, in Microstructure-Property Relationships in Titanium Aluminides and Alloys, edited by Y.W. Kim and R.R. Boyer (TMS, Warrendale, PA, 1991), pp. 3-30.

16. Binary Alloy Phase Diagrams, 2nd ed., edited by T.B. Massalski (ASM, Materials Park, OH, 1990), pp. 1304-1305.

17. B. Predel, in Landolt-Börnstein, New Series: Phase Equilibria, Crystallographic and Thermodynamic Data of Binary Alloys, edited by O. Madelung (Springer, Berlin, Germany, 1994), Gr. IV, Vol. 5, Subvol. d, pp. 49-50.

18. J.R. Taylor and A.T. Dinsdale, Z. Metallkde. 81, 354 (1990).

19. M. Kowalski and P.J. Spencer, CALPHAD 19, 229 (1995).

20. D. Basak, U.R. Kattner, J.L. McClure, D. Josell, and A. Cezairliyan, Int. J. Thermophys. 21, 913 (2000).

21. Handbook of Chemistry and Physics, 68th ed. (CRC Press, Boca Raton, FL, 1987-88).

22. Thermophysical Properties of High Temperature Solid Materials, edited by Y.S. Touloukian (Macmillan, New York, 1967), Vol. 1. 